Erratum

\title{
Erratum to "Pomegranate Extracts in the Management of Men's Urologic Health: Scientific Rationale and Preclinical and Clinical Data"
}

\author{
Nils Kroeger, ${ }^{1,2}$ A. S. Belldegrun, ${ }^{1}$ and A. J. Pantuck ${ }^{1}$ \\ ${ }^{1}$ Department of Urology, Institute of Urologic Oncology, David Geffen School of Medicine at the University of California, \\ 924 Westwood Boulevard, Suite 1050, Los Angeles, CA 90095-7384, USA \\ ${ }^{2}$ Department of Urology, University Medicine Greifswald, F.-Sauerbruch-Straße, 17489 Greifswald, Germany \\ Correspondence should be addressed to A. J. Pantuck; apantuck@mednet.ucla.edu
}

Received 23 May 2013; Accepted 23 May 2013

Copyright (C) 2013 Nils Kroeger et al. This is an open access article distributed under the Creative Commons Attribution License, which permits unrestricted use, distribution, and reproduction in any medium, provided the original work is properly cited.

The authors' names were incorrectly listed as Kroeger N., Belldegrun A. S., and Pantuck A. J.; the correct format is shown above. 


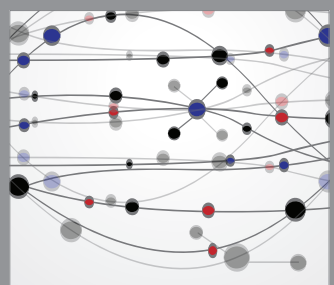

The Scientific World Journal
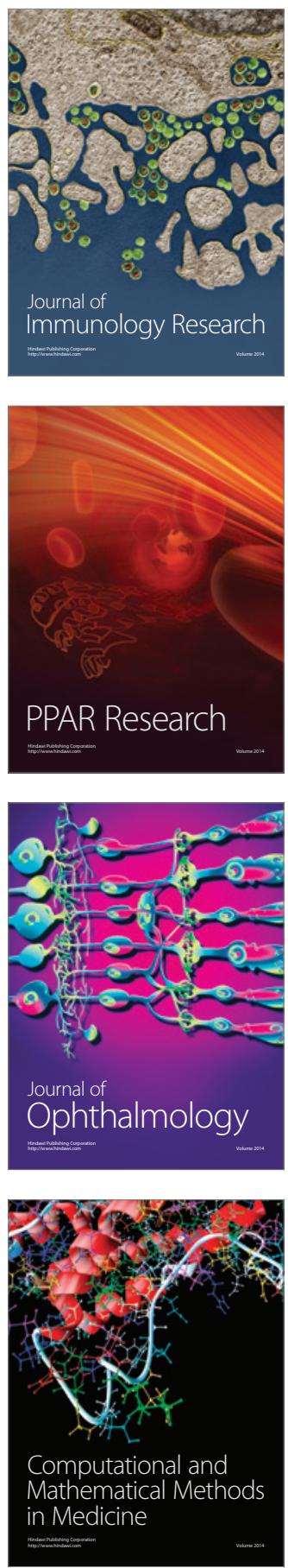

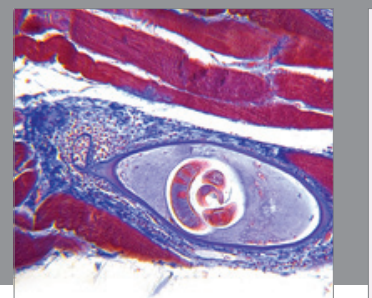

Gastroenterology

Research and Practice
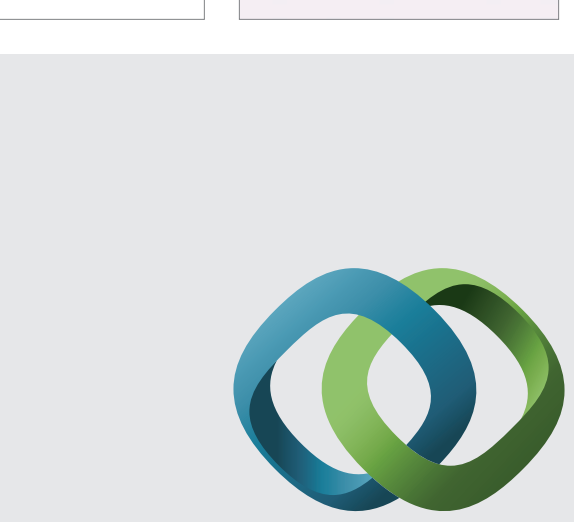

\section{Hindawi}

Submit your manuscripts at

http://www.hindawi.com
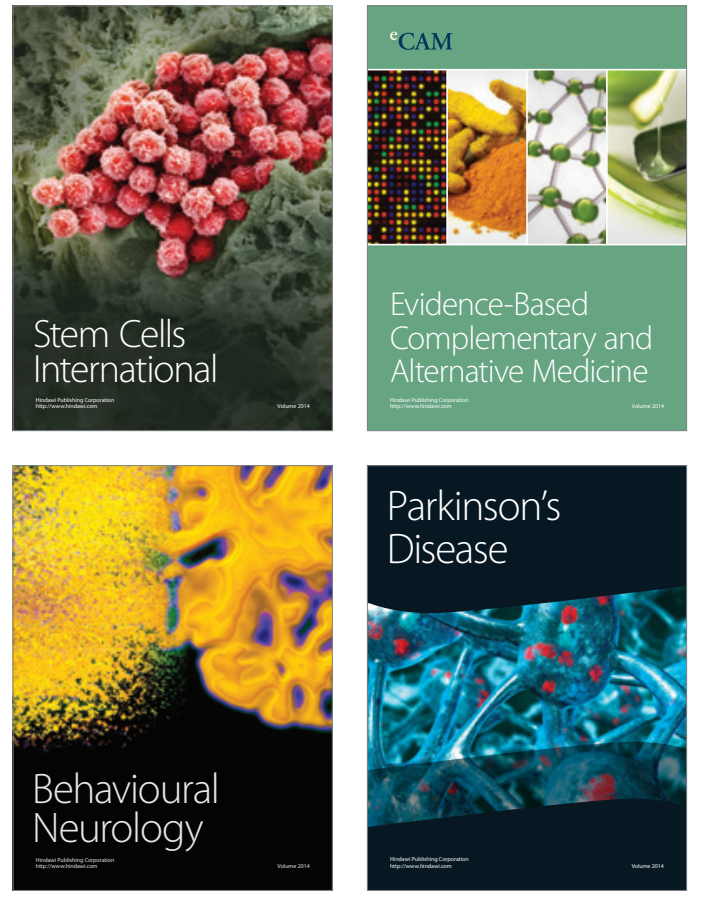
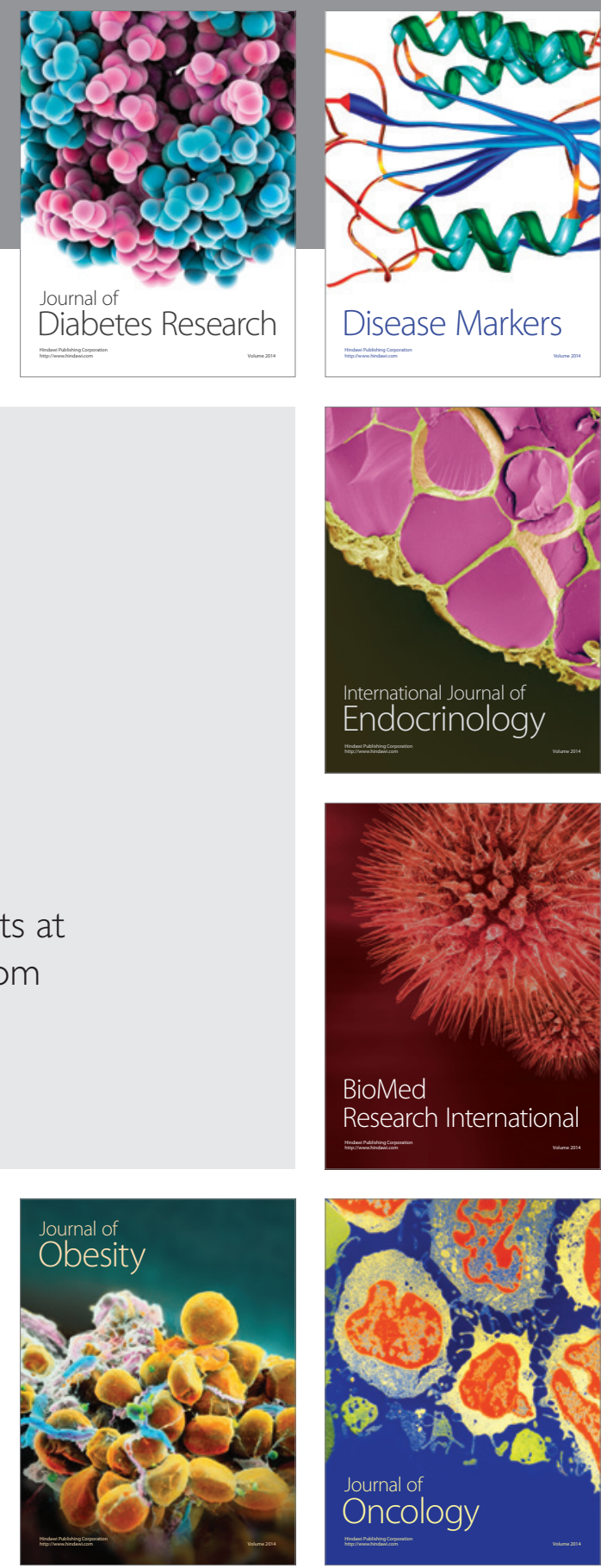

Disease Markers
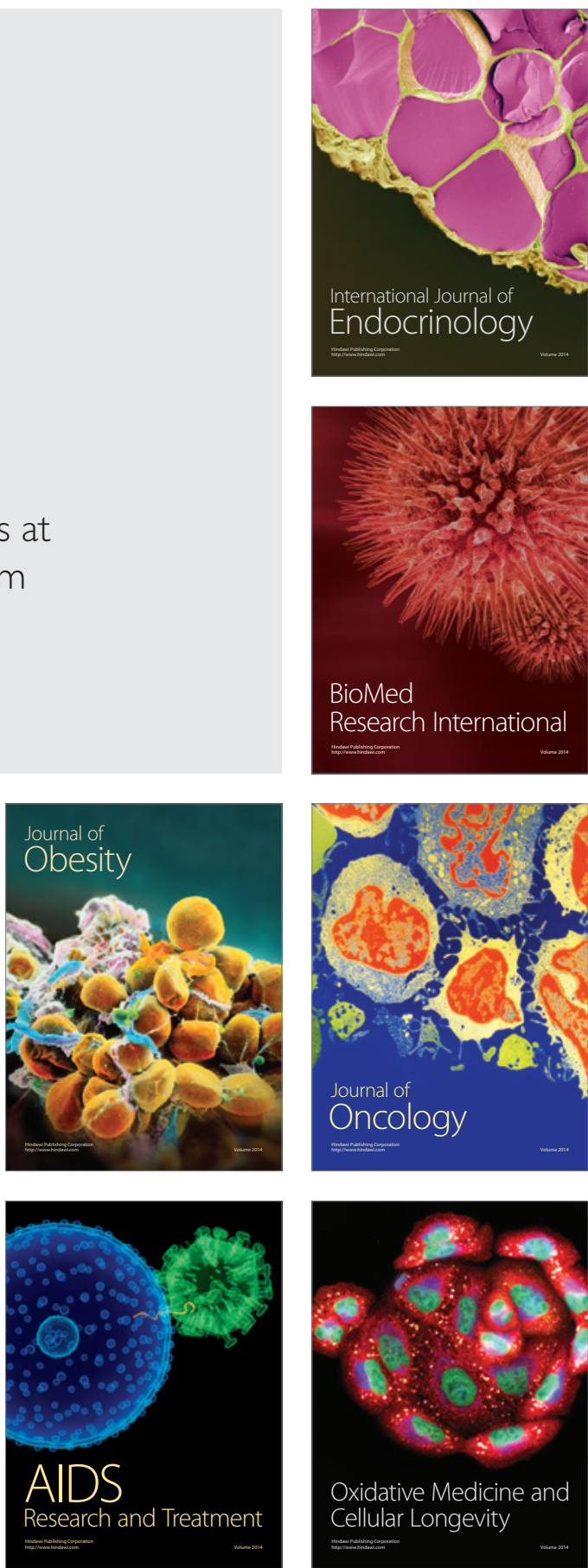